\title{
EDITORIAL
}

\section{New Emphasis on Privately Funded Applied Research: Would it Make India Industrially Sound and a Knowledge Economy?}

India has a sizeable scientific manpower and good numbers of research institutions in different basic as well as applied disciplines to carry on R\&D activities. Country's R\&D activities have shown an upward trend during the last decade. However, the progress is not at a rate that would lead this country to stand among leaders. More significantly, the upward trends in science research and education are not uniformly distributed, but are rather sparsely scattered so that the overall situation continues to be poor and worrisome. The situation does not appear any better in the context of industrial or applied research since a major share of industrial production in the country continues to be based on imported technology, used as such or cosmetically adapted to appear to suit the local requirements. Much of the indigenous innovation is more of the colloquial "jugaad" with poor quality control. With a view to change this situation, the government has now directed the research institutions and other researchers to get more involved in applied research so that the country's research efforts can be harnessed to make India a technologically selfsufficient and advanced country. To force the scientists take up applied and "socially relevant" research, the government has asked various institutions to generate at least half of their R\&D support from private industries rather than remain largely dependent upon the government grants. This is a paradigm shift.

Issues relating to failure of a majority of researchers and technologists working in India to make significant marks at global levels have been pondered upon and debated many times and many reports, policy documents etc have been produced over the past decades. None of these seem to have made any lasting effect. This may imply that the suggestions and road-maps in these recommendations failed to address the basic issues and, therefore, did not have the desired effect. While it cannot be ruled out that some of the suggestions have been more of knee-jerk reactions, the more likely reasons for absence of a sustained and widespread upward progress may lie in the implementation of the various suggestions and recommendations. Incomplete implementation or mis-implementation ensures that the expected transformation remains elusive. Now the government has directed various research institutions, which were so far funded primarily by the government, to engage themselves in applied research and seek support for R\&D activities from industries rather than continue to rely on the governmental support. The basic premise that has led to such unprecedented governmental order seems to be that only when forced, the scientific community would involve itself in "socially relevant" research which being funded by industry would ensure that the outcome will have direct commercial outputs.

There is no question that we need, on one hand a much greater participation of industries in promoting and utilizing indigenous research, and on the other, our scientists to undertake research that helps to improve the quality of life of country's citizens and provides for cutting edge technology for the industry. The other underlying reason for greater emphasis on industrial funding is that this would make the community of scientists more accountable to deliver the projected outcome within a reasonable time. These are good objectives but do these cover all aspects of research that the country needs to engage in? More importantly, have we planned well and prepared the scientists, the industry and the society in general for this paradigm shift? 
Ideally, a researcher seeks answers to curiositydriven question/s. In many cases, especially the Ph.D.oriented research, which accounts for the major share of R\&D activity in the country, the individual asking the question is different from those who are actively seeking answers. In either case, if those who are actually searching for answers do not develop curiosity and thereby become more deeply involved, they would be more like technicians than researchers. The overall $R \& D$ activities in the country have remained lusterless because many of the so-called researchers are indeed not distinguishable from technicians. The direction and levels of curiosity vary from individual to individual and, therefore, the actual questions sought to be answered and the intensity with which these are pursued also vary between researchers. By asking our scientists to primarily undertake applied and socially relevant research, are we not negating the inherent curiosity of a researcher?

What is the current level of involvement of industry in basic or applied research? Barring a few, most of our industries have not seriously engaged themselves in active $R \& D$ activities since a large share of their production activities is accounted for by imported technology and imported industrial hardware. The general public prefers "imported brands" as they are believed to be of better quality/utility than the "Desi" brands which by and large are taken as poor substitutes and do not have high enough "social status". Therefore, the industry aggressively advertises for imported items/technology. The fact that almost all equipment and reagents used for advanced research are imported also reflects the state of our preparedness. In the absence of incentive as well as demand, and compounded by less than the desired level of curiosity and motivation, the scientists and industry have not had enough interactions for developing tailor-made technological/innovative solutions for issues that are more relevant to the country. An example is the health-related research and its relation with the pharma industry. It is a general perception that as a country we have spent more governmental as well as industrial grants on research on infectious and other diseases that are less critical for India than on those that are endemic and affect a larger proportion. This is a consequence of the pharma industry being largely under control of multinationals whose primary interests lie somewhere else.

Given the existing vicious circle of poor demand, poor faith and therefore, poor incentives for industry as well as scientists, industry is unlikely to support long-term innovative research programmes which have high initial stakes without a guarantee of success. In the existing situation, the industrial support for research is more likely to be for short-term adhoc issues, which cannot lead to significant long-term technological advances.

It is a mis-conception that the country can do without enough investment in basic research. Even the industrially advanced countries where the purse for basic research was tightened some years ago are now realizing the mistake. We must not repeat it. Mankind continues to need basic research since we are still very far from understanding even a small part of what all goes on in nature. Basic research is also essential for training young minds so that they develop scientific temperament. More significantly, if we wish to develop new technologies on the basis of knowledge base created by others, we can at best achieve the status of followers but would never get to the leadership. The country cannot develop and expand its knowledge base by merely "importing experts", whether person of Indian origin (PIO) or otherwise. This has to happen primarily by indigenous efforts. Of course, the basic research has to be innovative and which indeed leads to new understanding so that it may provide novel directions for application in the long-term. We cannot continue to remain engaged in sub-standard and repetitive research which only serves to fulfill the mandatory requirements for seeking a job and promotions and thus waste money on pseudo-research. Instead of relying merely on quantity, we need to learn to objectively assess the quality. Unless the quality of basic research in all spheres improves, "socially relevant" research would continue to lack innovation, originality and, therefore, utility. We need to develop accountability-based basic, industry and goal-oriented research. Several recent analyses have pointed out that industry-driven research carries the risk of the outcomes being tailor-made. Therefore, like the need for balance between basic 
and applied goal driven research, a good balance is also required in government and industry funding for research.

I think the most important factors responsible for the poor quality of country's basic as well as applied R\&D activities, and therefore, the "make in India" scenario, are our rapidly deteriorating education and the human resource utilization systems. These issues have been discussed in past, including by the science academies in the country and, therefore, do not need elaboration. Unfortunately, however, in spite of the wide discussions, the necessary reforms have not been taken up with any long-term perspective. The so-called "corrective" measures being introduced from time to time are at best ad-hoc, and even when they have some promise, we seem to have an unsurpassable ingenuity to pervert the well-intentioned measures. We are not preparing the large mass of students to be curious and to have an integrated understanding. As a result, a majority of our graduates and post-graduates remain unemployable. Fortunately, some students turn out to be potential achievers, in spite of us rather than because of us! However, our social and academic environment ensures that nearly all of them leave the country and make us indirectly proud when a PIO achieves international acclaim. This has gone on for many decades. Should the academic community and the country as a whole not feel seriously concerned that in spite of all the developments we claim to have achieved as a free nation, we are still not good enough to provide conducive environment where our citizens can achieve while working within the country, as they do when outside of it? We have failed because we neither educate our young generation well nor provide a promoting environment to let them bloom optimally. This needs to change.
I firmly believe that education at all levels is a social obligation. Neither society nor government should shirk its responsibilities and let it drift with little or poor quality control. Our human resource utilization policies also need an overhaul so that we do not force a square peg in a round hole. While the population growth needs to be checked, we also need to channelize a larger proportion of youth to selfemployment paths rather than attempting to provide higher education degrees of dubious quality to the unmanageable numbers. Such worthless degrees actually have a negative impact. Without comprehensive reforms in these sectors, we would not achieve much, no matter what policies are adopted for improving and financing our R\&D sector.

Boasting of the "glorious" achievements of science in ancient India does not help or improve our present state. What we actually need is to rationally examine the scientific and technological achievements of ancient India and use the validated knowledge in the context of our contemporary understanding. Indulging in "pseudo-science" on the basis of poorly documented "scientific achievements" of our ancestors does more harm than good.

It is necessary to have well-defined missions and targets. However, to achieve those, we need adequately trained and enthusiastic researchers, optimal material and social environments, and comprehensive long-term policies with adequate plans for their proper implementation. Currently, we seem to be running short in all, especially the last.

We wish you all a happier and more productive 2016.

S C Lakhotia Editor-in-Chief 